\title{
RELATIONSHIPS IN INCLUSIVE CLASSROOMS
}

\author{
Graça Duarte Santos ${ }^{1}$, Susana Sardinha ${ }^{2}$ and Silvia Reis ${ }^{3}$ \\ ${ }^{1}$ Universidade de Évora, Portugal; ${ }^{2}$ APPACDM Associação Portuguesa de Pais e Amigos do Cidadão Deficiente Mental de \\ Setúbal, Portugal; ${ }^{3}$ APPC -Associação Paralisia Cerebral de Beja, Portugal
}

Key words: Classroom relationships, autism, cerebral palsy, mental disability, hyperactivity disorder.

\begin{abstract}
Climate in the classroom is one of the determining factors in the development of practices in Inclusive Education. Many factors contribute to the climate in the classroom. However, there are predominance on affective-relational factors, with impact on action, norms and values, social interactions and learning processes. In this paper, the authors reflect on four studies which aim to identify and evaluate the relationship between several agents in the teaching-learning process (regular teachers, special education teachers and peer students) and the students with Autism, Cerebral Palsy, Mental Disability and Attention Deficit Hyperactivity Disorder. The studies were held in Primary Portuguese schools. The results are presented and discussed in their similarities and differences. The discussion shows that relationships between teachers and children with Special Education Needs (SEN) differ from those between teachers and typical children, but also according to different SEN. In general, there are not significant differences between regular teachers and special education teachers.
\end{abstract}

\section{Introduction}

The growing need for reflection and debate on the issue of Inclusive School as an education that adequately responds to the characteristics, needs and interests of each and every one emphasizes the importance of a careful analysis of actual practices in the classroom framed on a perspective of the child in Development in a specific context. Effectively the inclusion of children with special educational needs in the classroom is a crucial goal, as it provides important factors that help them adapt: being taught together with other children, feeling part of the class and being recognized by it, with the resources it furnishes and the issues it entails (Ainscow, Booth and Dyson, 2006). However, work in inclusive classroom requires a real deep acceptance of all individuals in their variety and diversity of needs, opportunities and difficulties.

In Portugal, specific law (Order 105/97 and Decree Law 3/2008) proclaim the need for inclusion for children with special needs in the mainstream education system, calling for professional specialists who provide individual support on the basis of the child's characteristics. The cooperative work of the teachers (regular and special education teachers) aims to achieve educational and social inclusion for children with special educational needs, meeting their instructional needs, making the most of their abilities and helping them attain independence, emotional stability and equal opportunities.

The climate in the classroom is one of the determining factors in the development of the inclusive practices. The creation and maintenance of a socio-emotional climate in which all students can feel psychologically safe, valued and accepted, ensure active involvement and sense of belonging is therefore a sine qua non condition for the successful development of any inclusive practice (Santos, Ljusberg and Candeias, 2009). Many factors contribute to the climate in the classroom. However, there are predominance on affective-relational factors, with impact on action, norms and values, social interactions and learning processes.

The affection has assumed an important role in education; it is through the affection that student have access to success. A balanced and healthy climate gives to student a feeling of well-being, communication and promotion of social skills. Pianta (1994), refer that primary teachers may be at an advantage in establishing a closer relationship with the students, given the situation of a single teacher and due to age of students.

Several studies shows the influence of relationships established between teacher and student in peer relationship which is reflected in the level of acceptance or rejection, saying that less positive relationship between teacher and student will have negative effects on the social and emotional development of children (Howes, Hamilton and Matheson, 1994). Consequently, their level of inclusion in class is affected, for example, in a conflicting or dependent relationship with the child, their peers do not consider him/her as part of the class (Pianta and Stuhlman, 2004).

For the child with SEN, interactions with peers, help them to overcome barriers imposed by the limitations that 
present and enable them to develop linguistic, social, emotional and academic skills up Pianta, R. \& Hamre, B. (2009). Understand and promote a good relationship between peers is crucial to ensure the success of inclusion of children with any developmental disorder (Laws and Kelly, 2005) being this relationship also dependent on the experiences and activities that the teacher proposes, as well as its own relationship with students individually and in groups. Furthermore, the very characteristics of the developmental disorder and individual characteristics of children can contribute to the facilitation or limitation of all social relationships with peers or teachers.

Children with Autism Spectrum Disorder, who have qualitative impairments in social interaction communication and behaviour (with restricted, repetitive and stereotyped patterns of behaviour, interests and activities) have difficulty in understanding the nuances of social behaviour; giving the impression that they are uninterested in interacting with others. Moreover, some of their unusual behaviours and/or behavioural excesses may also interfere with positive relationships with others. Sometimes they try to communicate with others, but in ways that are not appropriate in the context (Robertson, Chamberlain and Kasari, 2003; Santos, Longobardi, Pasta, et al., 2010).

Regarding children with ADHD Barkley studies (2002) report that relationship issues with friends or adults are the most distressing aspects that they have to deal with. Rudasill, Reio, Stipanovic, et al. (2010), report that the difficulties presented in terms of social interaction are perceived as unsatisfactory being these children in constant situation of rejection and victimization by their peers.

Also the inclusion of students with Cerebral Palsy and Mental Disability is a real challenge due to the impact of these disorders in multiple areas, beyond the obvious neuromotor or cognitive impairment.

This paper present a comparative reflection between four studies which aim to identify and evaluate the representation of relationship between several agents in the teaching-learning process (regular teachers, special education teachers and peer students) and the students with four different SEN: Autism Spectrum Disorders (ASD), Cerebral Palsy (CP), Mental Disability (MD) and Attention Deficit Hyperactivity Disorder (ADHD). In each study, we intent to evaluate the representation of teacher-student relationships on the dimensions of conflict, closeness and dependency. The intention was also to evaluate the relationship between the level of peer acceptance and rejection in the classroom and recreation.

\section{Methods}

These fours researches ${ }^{1}$ aims to know the representations of relationships that are established in context of inclusive

${ }^{1}$ (Sardinha, 2011; Reis, 2012; Fraga, 2012; Rei, 2012) classroom between teacher(s) and student(s), and between peers. Each study investigates several classrooms where children are included with one of these SEN. The objectives, methodology and instruments used were the same in the four investigations. Schools are different but in the same region.

From this overall objective, the following specific objectives were defined: (a) assess if there are significant differences in representation that teachers have of their relationship with the child with SEN and the other children in classroom in terms of conflict, closeness and dependence; (b) assess if there are significant differences between representation that regular teachers and special education teachers, have of their relationship with the child with SEN in terms of conflict, closeness and dependence; (c) assess if there are differences in choices (preferences and/or rejections) between the peer group in relation to children with SEN.

\section{Sample}

The studies were held in Primary Portuguese schools. They involved the next samples with the following characteristics:

(a) Study 1: involved 20 children with ASD, their classmates $(\mathrm{N}=304)$, their regular teachers $(\mathrm{N}=14)$ and special teachers $(\mathrm{N}=10)$. The children are $55.6 \%$ male and $44.4 \%$ female. $30 \%$ are in the first grade, $15 \%$ in second; $40 \%$ in third and $15 \%$ in fourth.

(b) Study 2: involved 13 children with $\mathrm{CP}$, their classmates $(\mathrm{N}=214)$, their regular teachers $(\mathrm{N}=13)$ and special teachers $(\mathrm{N}=13)$. The children are $52.4 \%$ male and $47.6 \%$ female. $26.9 \%$ are in the first grade, $24.2 \%$ in second; $16.3 \%$ in third and $26.9 \%$ in fourth.

(c) Study 3: involved 21 children with MD, their classmates $(\mathrm{N}=198)$, their regular teachers $(\mathrm{N}=21)$ and special teachers $(\mathrm{N}=7)$. The children are $57.4 \%$ male and $42.6 \%$ female. $6.3 \%$ are in the first grade, $20.5 \%$ in second; $42 \%$ in third and $31.2 \%$ in fourth.

(d) Study 4: involved 16 children with ADHD, their classmates $(\mathrm{N}=244)$, their regular teachers $(\mathrm{N}=14)$ and special teachers $(\mathrm{N}=8)$. The children are $59.5 \%$ male and $40.5 \%$ female. $6.9 \%$ are in the first grade, $43.5 \%$ in second; $16.5 \%$ in third and $33.1 \%$ in fourth.

All students were between 6 and 12 years old.

\section{Instruments}

The data were collected by two tools.

Student-Teacher Relationship Scale (STRS). To assess perception that teachers have of their relationship with certain student and with all their students, regular and special education teachers were asked to rate 28 items on Student-Teacher Relationship Scale (Pianta, 1996) using a Likert scale. The STRS evaluates both the teacher's feelings about a specific student, and the behaviour and 
feelings that the teacher believes that the student shows towards the teacher. Specifically, the total score obtained for 28 items clarifies teachers' representations of their relationship with the SEN student, and measures the three dimensions of the relationship: level of Conflict (negative aspects of relationship, such as coldness or hostility), Closeness (warmth, mutual trust, emotional communication) and Dependency (to what extent and in what situations the student turns to the teacher as a source of comfort or security).

Sociometric technique. To evaluate the relationships between peers, we used a sociometric technique that allowed us to analyse the perceptions that students have of their relationship with their peers in classroom context and in playground, at two levels: acceptance and rejection. To each child, we asked to tell the frequency of choose of each one of their colleagues to play in playground or to be near her/him in class. Answers were given through a frequency scale (Likert-type of 5 point) where possible answers were also attached to drawings of faces with five expressions (open smile-sad).

Each classmate answered the questions. It was determined then if and by what percentage of classmates the ASD/ CP/MD or ADHD child, was mentioned. All class members answered except autistic children.

\section{Procedure}

Each study involved several stages: contacting schools and assembling samples of children with each type of SEN, presenting the project to schools administrators and teachers, collecting and analysing data.

Unlike STRS, which was filled by the teachers for all the students, for the sociometric technique it was required parental consent.

For data analysis of sociometric technique, in order to get a clearer representation of preferences and rejections, it was decided to group extreme items. We considered thus three levels: level considerate as rejection, consisting of items 'never' and 'rarely', level of indifference, comprising the item 'sometimes' and level of acceptance with items 'often' and 'always'. For the analysis of this tool were performed frequency analyses.

\section{Results}

Regarding the study on the perception of teachers towards their relationship with students, the conflict subscale results only showed statistically significative differences in regular teachers on their relationship with ASD and ADHD children, perceiving as more conflictual that with children without ASD and ADHD $F(2,301)=5.05$, $P<0.01$ and $F(2,249)=3.82, P<0.05$ respectively. It was found with ADHD a significant negative correlation between conflict sub-scale and student gender ( $r=-0.23, P<0.01)$, showing that regular teachers tend to perceive their relation with boys as more conflictual. The children's educational level also has a significative positive correlation $(\mathrm{r}=0.29, P<0.01)$, revealing that the degree of conflict is higher in more advanced years of education $(r=-0.20, P<0.01)$.

The results of the proximity subscale showed statistically significant differences in the perception of teachers in their relationship with children with ASD, perceiving as significantly nearest the relationship with children without ASD F $(2,301)=5.49, P<0.01$. For children with ASD they perceive their relationship more close as lower class year $(r=0.24, P<0.01)$.

The results of the dependency subscale showed statistically significant differences in all four studies regarding the perception of teachers in their relationship with children with SEN, perceiving a more dependent relationship in children with ASD (the higher the lower the year of the class, $r=-0.42, P<0.01)$; more dependent in children with $\mathrm{CP}(t(2,225)=2.63, P<0.01)$; more dependent in children with $\mathrm{MD}(t(2,174)=4.12, P<0.000)$.

Regarding the study of the differences in the perception of regular teachers and special education teachers face their relation to students with SEN, only have statistically significant differences on sub-scale of dependency for children with $\mathrm{MD}(t(1,22)=-3.01, P<0.007)$ which are perceived as more dependent by regular teachers than by special education teachers.

It was also found that special education teacher of child with ADHD perceive the child's dependence as decreasing significantly with increasing the educational level $(r=-0.708, \quad P<0.05)$ as well as special education teachers of children with ASD perceive significantly more dependent relationship in children on 2nd grade compared to children with ASD attending classes from 3rd grade $F$ $(4,14)=3.45, P<0.01$.

Regarding the sociometric study of choices between the peer group in relation to children, there were differences among children with MD, and children with ADHD and their respective colleagues, and in both cases less preferred by peer. In the context of classroom, students with MD are more often rejected by their peers $(68.3 \%)$ and $50 \%$ are rejected in the playground (of which $63.5 \%$ are boys). The children with ASD, although do not differ significantly, have more rejections in the context of recreational compared with the classroom context. It was also found that students with $\mathrm{CP}$ in context of classroom are mostly accepted, getting the highest rejection percentages with girls in the classroom context.

\section{Conclusions}

In the meta-analysis of the four studies conducted, we verified some important significant differences: regular teachers have the perception that their relationship with 
all children with SEN is more dependent than children without SEN. According Pianta and Steinberg (1996), high results in subscale dependence are indicators that student reacts to the separation of teacher, asking for help even if he/she do not need, also revealing that teacher cares about the excessive dependence of the child.

Relationships between teachers and children with ASD differ significantly from those between teachers and typical children, being more conflictual and dependent and also less close, intensifying latter two aspects in the early years of schooling.

Also with children with ADHD their relationship is more conflictual, especially in years of more advanced schooling.

Interestingly, there were no significant differences between the perception of relationship of regular teachers and special education teachers, except for children with MD which regular teachers perceive as more dependents.

Still regarding dependence variable, special education teachers perceive children with ADHD and ASD as less dependent with increasing schooling.

Regarding the acceptance of children with SEN by their peers, it was found that this is more difficult for children with MD (mainly in classroom context and for males) and ADHD (in most classes these children do not been chosen by their peer group). However, children with CP are good levels of acceptance, not finding differences between the relationships established in the classroom and playground.

Studies of Pianta and Stuhlman (2004) show that children with behavioural problems have a positive relationship between conflict and dependence. This conflicting and sometimes dependent relationship maintained with the child with ADHD may be perceived by their peers as nuisance leading them to reject (Koomen and Leij, 2008). Also Murray and Grennberg (2006) stress that the unfavourable relationships of these children with teachers affect their reputation among colleagues, leading to not be accepted in peer group. Our study supports these estimates which $50 \%$ of children with ADHD have significant problems in their social relationships.

Children with CP, however, have good levels of acceptance either in classroom or on playground.

Although not verify quantitatively differences between overall results of regular teachers and special education teachers, a more careful analysis of results suggested us that they perceive differently the relationships established with the same child, pointing to the need for further in future studies.
This investigation did not analyse organizational variables that can influence the relationship between teacher and the child with SEN (such as special education program, school and classroom facilities, type of cooperation between regular and special education teachers, and teachers' beliefs and experience).

The interpersonal relationship, in fact, is modulated by interactions between students and between teacher and students. These interactions are crucial in number, but essentially qualitatively, which is closely related to multiple dimensions of the development of each participant. The relationship between teacher and the child with SEN is a factor that influences the developmental of SEN student's social status in class, facilitating inclusion and future positive relationships between all children.

It is an internal and external task of teacher the constant improvement to this purpose.

\section{Conflicts of interest}

There is no conflict of interest.

Address for correspondence

Grace Duarte Santos

Department of Psychology, University of Évora, Portugal

Email:mgss@uevora.pt

\section{References}

Ainscow, M., Booth, T. \& Dyson, A. (2006) Improving Schools, Developing Inclusion. London: Routledge.

Fraga, P. S. (2012) Relacionamentos em Salas de Aula: um estudo sobre o Processo Inclusivo da criança com Deficiência Mental. Master Tesis, University of Évora.

Howes, C., Hamilton, C. E. \& Matheson, C. (1994) 'Children's relationships with peers: differential associations with aspects of the teacher-child relationship.' Child Development, 65, pp. 253-63.

Koomen, H. \& Leij, A. (2008) 'Teacher-child relationships and pedagogical practices: considering the teacher's perspective.' School Psychology Review, 37 (2), pp. 244-60.

Laws, G. \& Kelly, E. (2005) 'The attitudes and friendship intentions of children in United Kingdom mainstream schools towards peers with physical or intellectual disabilities.' International Journal of Disability, Development and Education, 52 (2), pp. 79-99.

Murray, C. \& Grennberg, M. (2006) 'Examining the importance of social relationships and social contexts in the lives of children with high-incidence disabilities.' The Journal of Special Education, 39 (4), pp. 220-33. 
Pianta, R.C. (1994) 'Patterns of relationships between children and kindergarten teachers.' Journal of School Psychology, 32, pp. 15-31.

Pianta, R. \& Hamre, B. (2009) 'Conceptualization, measurement, and improvement of classroom processes: standardized observation can leverage capacity.' Educational Researcher, 38, pp. 109-19.

Pianta, R. C. \& Steinberg, M. S. (1996) 'Teacher-child relationships and the process of adjusting to school.' New Directions for Child Development, 57, pp. 6180.

Pianta, R. \& Stuhlman, M. (2004) 'Teacher-child relationships and the children's success in the first years of school.' School Psychology Review, 33 (3), pp. 444-58.

Rei, M. C. (2012) Relacionamento com crianças com Hiperactividade: um Estudo em contexto de Sala de Aula Inclusiva. Master Tesis, University of Évora.

Reis, S. C. (2012) Inclusão escolar: um olhar sobre os relacionamentos em sala de aula das crianças com Paralisia Cerebral. Master Tesis, University of Évora.
Robertson, K., Chamberlain, B. \& Kasari, C. (2003)

'General education teachers' relationships with included students with autism.' Journal of Autism and Developmental Disorders, 33 (2), pp. 123-30.

Rudasill, K. M., Reio, T. G. Jr, Stipanovic, N. \& Taylor, J. (2010) 'A longitudinal study of student-teacher relationship quality, difficult temperament, and risky behavior from childhood to early adolescence.' Journal of School Psycology, 48, pp. 389-412.

Santos, G., Ljusberg, A. \& Candeias, A. (2009) Classroom Climate in Inclusive Settings. Proceedings of International Conference Changing Practices Inclusive Schools. Évora: University of Évora.

Santos, G., Longobardi, C., Pasta, T., Sardinha, S. \& Gastaldi, F. (2010) 'The inclusion of autistic children in the classroom: Italian and Portuguese realities.' International Journal of Developmental and Educational Psychology, XXII (3), pp. 793-801.

Sardinha, S. (2011) Relacionamgitos em sala de Aula Inclusiva: contributos para a avaliação do processo inclusivo da criança com Perturbações do Espectro do Autosimo. Master Tesis, University of Évora. 